\title{
The 2019 JPED Editors' Choice Awards
}

Published online: 4 March 2020

(C) ASM International 2020

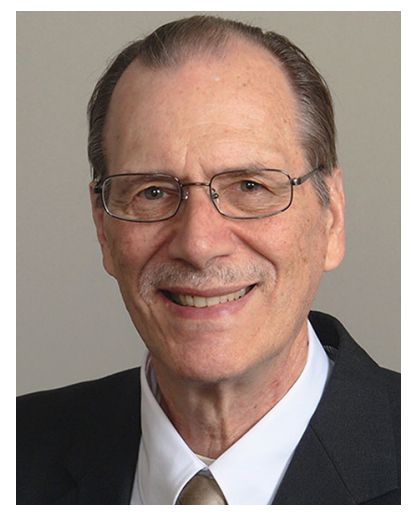

The Editors' Choice Awards for 2019 are listed below. The selection process considered several factors including quality of the research, text, and figures, as well as originality and relevance to the field. For example, the paper by Bian et al. is one of the few papers to recognize the effect of steep concentration gradients on the analysis of diffusion data. Six awards are given annually based on my opinion and that of our Deputy Editor, Dr. Ursula Kattner.

Jindrich Leitner, David Sedmidubsky, Thermodynamic Modeling of Oxidation of Tin Nanoparticles, Phase Equilib. Diff., 2019, 40(1), p 10-20

Baixue Bian, Yuling Liu, Yong Du, Qianhui Min, Huixin Liu, Shiyi Wen, Peng Zhou, Measurement of the Interdiffusion Coefficients in Mo-Ti and Mo-Ti-Zr Beta Phase Alloys from 1273 to 1473 K, Phase Equilib. Diff., 2019, 40(2), p 206-218
Wei-Wei Zhang, Erwin Povoden-Karadeniz, Huixia Xu, Ming Chen, Thermodynamic Modeling of the La-Co-O System, Phase Equilib. Diff., 2019, 40(2), p 219-234

Denis Shishin, Taufiq Hidayat, Ata Fallah-Mehrjardi, Peter C. Hayes, Sergei A. Decterov, Evgueni Jak, Integrated Experimental and Thermodynamic Modeling Study of the Effects of $\mathrm{Al}_{2} \mathrm{O}_{3}, \mathrm{CaO}$, and $\mathrm{MgO}$ on Slag-Matte Equilibria in the Cu-Fe-O-S-Si-(Al, Ca, Mg) System, Phase Equilib. Diff., 2019, 40(4), p 445-461

Peter Kainzbauer, Klaus W. Richter, Herta S. Effenberger, Gerald Giester, Herbert Ipser, The Ternary Bi-MnSb Phase Diagram and the Crystal Structure of the Ternary $\mathrm{T}$ Phase $\mathrm{Bi}_{0.8} \mathrm{MnSb}_{0.2}$, Phase Equilib. Diff., 2019, 40(4), p 462-481

Chuan Zhang, Jiashi Miao, Shuanglin Chen, Fan Zhang, Alan A. Luo, CALPHAD-Based Modeling and Experimental Validation of Microstructural Evolution and Microsegregation in Magnesium Alloys During Solidification, Phase Equilib. Diff., 2019, 40(4), p 495-507

Letters confirming the awards have been sent via email to the corresponding author of each paper (underlined above). Co-authors can receive a copy of the letter from the corresponding author or by sending a request to jemorral@gmail.com.

In addition to the award, papers are given "Free Access" via the Springer/JPED website http://www. springer.com/materials/journal/11669 or SpringerLink. Free access means that papers can be viewed 24/7 worldwide by anyone with an internet connection. 
We at JPED thank all the authors who sent us their manuscripts last year and heartily congratulate all who received an Editors' Choice Award for 2019. Also, we thank our valued reviewers for their efforts toward making JPED a quality publication.

\section{John Morral}

Editor-in-Chief

Journal of Phase Equilibria and Diffusion

Publisher's Note Springer Nature remains neutral with regard to jurisdictional claims in published maps and institutional affiliations. 